\title{
Frequency of Respiratory disorders among daily life occupational workers of Rawalpindi Pakistan
}

\section{Rizwana Shahid $^{1 *}$, Sana Bilal ${ }^{1}$, Syed Arshad Sabir ${ }^{2}$, Mahjabeen Qureshi ${ }^{3}$, Umaira Ali $^{4}$}

${ }^{1}$ Assistant Professor Community Medicine, Rawalpindi Medical University

${ }^{2}$ Dean of Community Medicine \& Public Health, Rawalpindi Medical University

${ }^{3}$ Senior Demonstrator Community Medicine, Rawalpindi Medical University

${ }^{4}$ Postgraduate Trainee Community Medicine, Rawalpindi Medical University

*Corresponding Author: Rizwana Shahid, Assistant Professor Community Medicine, Rawalpindi Medical University, Rawalpindi

Received date: 03 October 2021; Accepted date: 03 November 2021; Published date: 08 November 2021

Citation: Shahid R, Bilal S, Sabir SA, Qureshi M, Ali U (2021) Frequency of Respiratory disorders among daily life occupational workers of Rawalpindi Pakistan. J Comm Med and Pub Health Rep 2(11): https://doi.org/10.38207/JCMPHR/2021/0211206

Copyright: ( 2021 Rizwana Shahid. This is an open-access article distributed under the terms of the Creative Commons Attribution License, which permits unrestricted use, distribution, and reproduction in any medium, provided the original author and source are credited.

\begin{abstract}
Objective: To determine the frequency of respiratory disorders among daily life occupational workers of Rawalpindi city

Subjects \& Methods: A cross-sectional descriptive study was carried out among 100 daily life occupational workers at Rawalpindi city during March 2019 through convenience sampling. The garment shop workers, carpenters, furniture polishers, barbers, hotel cooks, street food sellers, poultry workers, karyana, and tandoor workers were also interviewed to ascertain their job-related respiratory problems, family history, and duty hours per day through consecutive sampling. Data were analyzed by using SPSS version 25.0 and Microsoft Excel 2010. The mean difference in working hours of garment shop workers and barbers was verified by an independent sample t-test. $\mathrm{P}<0.05$ was considered significant.
\end{abstract}

Results: Of the total 100 daily life occupational workers, the majority (20\%) was constituted by garment shop workers and barbers (16\%). The median age of workers was $30 \pm 6.9$ years. Their mean working hours per day were $12.34 \pm 2.72$ hours. About 2 garments, 1 poultry, and 1 tandoor worker were known as asthmatic. Family history of asthma was positive among 4 garments, 4 barbers, 3 carpenters, 2 karyana store, 2 furniture polishers, 1 poultry, and 1 tandoor worker. About $17 \%$ of workers had to wheeze for the last 12 months. Approximately $13 \%$ of workers used to wake up with chest tightness while $24 \%$ with an attack of cough during the last 12 months. $90 \%$ of barbers and $50 \%$ of garment workers had a history of cough at the workplace. However, the mean difference in their duty hours was determined to be statistically significant $(\mathrm{P}=0.002)$

Conclusion: Various occupational workers are susceptible to respiratory problems due to exposure to toxic agents at their workplace.

Keywords: respiratory disorders, wheeze, cough, occupational workers, working hours.

\section{Introduction}

Occupational asthma has become the leading respiratory malaise both in developed and underdeveloped regions of the world. This health problem is attributed to numerous agents in our environment like fumes, smoke, air pollutants, noxious substances, and dust particles [1]. About $5-10 \%$ of the population is affected by asthma globally out of which $2-15 \%$ is occupational in nature [2]

Healthcare workers are also likely to develop work-related asthma due to the use of disinfectants, sterilizing agents, antibiotics, and aerosolized drugs[3]. Our Physicians, respiratory therapists [4], endoscopists, radiologists, and nurses are at high risk of developing occupational asthma in healthcare settings [5]. Smoking also contributes towards the development of occupational asthma apart from genetics. An international study revealed $12.54 \%$ positive cases of occupational asthma among employees of food, cement, and ceramic industries [6]. The poultry workers are highly susceptible to respiratory disorders particularly obstructive lung diseases due to exposure to bioaerosols at workplace [7]. Carpenters are also at risk of developing mesothelioma due to inhalation of toxic asbestos fibers even during wall insulation. In addition to allergic symptoms, these occupational workers are highly vulnerable to significantly deranged pulmonary function tests [8].

Chronic obstructive lung diseases among 24-45 \% non-smokers are attributed to various hazardous inhalational agents at their workplace [9]. Textile workers are known as highly vulnerable to obstructive pulmonary maladies[10]. A study by Bakirci $\mathrm{N}$ et al revealed that about $20 \%$ of the newly hired cotton mill workers left their job in the first month of their employment and about half of the employees got termination from their contract due to the development of vocational lower respiratory tract infections [11].

Research by Khan $\mathrm{M}$ et al among female workers employed in Faisalabad and Lahore spinning mills concluded that long working duration was considerably linked to the breathing difficulties [12]. Although numerous researches are carried out to explore the adverse health effects among various industrial workers but the discovery of 
inhalational diseases among other occupational workers like barbers, furniture polishers and hotel chefs are insubstantial. The present study is therefore intended to determine the frequency of respiratory ailments prevailing among daily life occupational workers of Rawalpindi city. The findings of this study would really enable our

\section{Subjects \& Methods}

A cross-sectional descriptive study was carried out among 100 daily life occupational workers 20-40 years old belonging to diverse occupations at Rawalpindi city during March 2019 through convenience sampling. These included garment shop workers, carpenters, furniture polishers, barbers, hotel cooks, street food sellers. In addition, workers of poultry form, karyana stores, and tandoors were also interviewed to ascertain their job-related respiratory problems. Data was collected by using a self-structured questionnaire. The data was collected from study subjects regarding policymakers to devise appropriate strategies for lessening the inhalation of menacing agents at the workplace and educating the susceptible population about compliance with precautionary measures.

their age, duty hours per day, complaint of cough and wheeze at the workplace, history of waking up with cough or chest tightness during last 12 months, family history of asthma, the reason for breathlessness, and medication for respiratory symptoms. Informed consent was taken from all the workers before the face-to-face interview. Data were analyzed by using SPSS version 25.0 and Microsoft Excel 2010. The mean difference in working hours of garment shop workers and barbers was compared by an independent sample t-test. $\mathrm{P}<0.05$ was taken as significant.

\section{Results}

The median age of respondents was $30 \pm 6.9$ years. Mean working hours per day were $12.34 \pm 2.72$ hours. Workers enrolled in this

research were indulged in diverse occupations as depicted below in Figure 1.

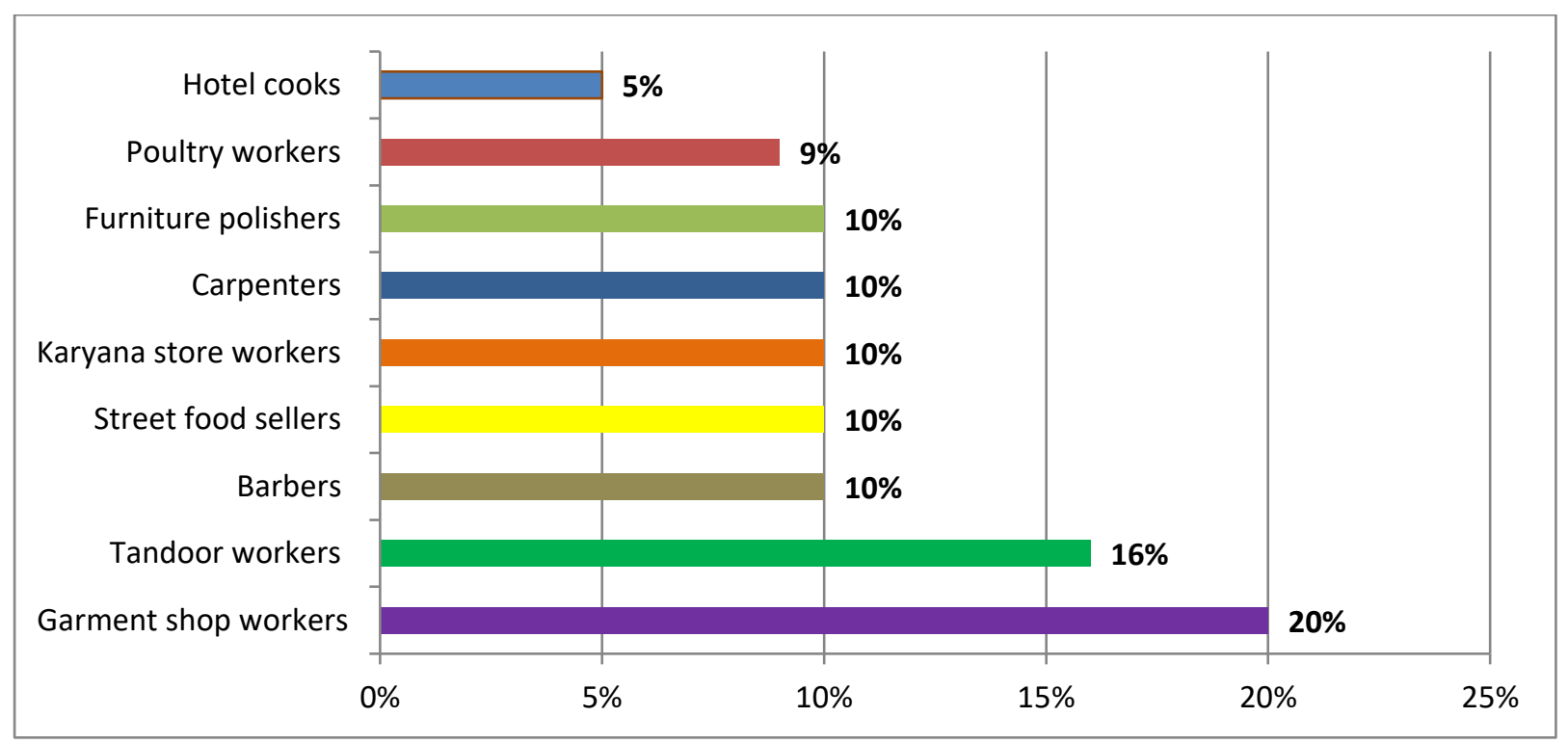

Figure 1: Occupations of different daily life workers

2 garment shop workers, 1 poultry worker, and 1 tandoor worker were determined to be known asthmatic and on anti-asthmatic medication. However, 4 garment shop workers, 4 barbers, 3 carpenters, 2 karyana store workers, 2 furniture polishers, 1 poultry worker and 1 tandoor worker had a family history of asthma. Only 4 workers were found to have episodes of breathlessness for no apparent reason. $17 \%$ of workers had wheezing since last 12 months as illustrated below in Table 1 out of which only $3 \%$ were seeking treatment for wheezing.

Table 1: Wheezing since last 12 months among daily life occupational workers $(\mathrm{n}=17)$

\begin{tabular}{|l|l|}
\hline Daily life occupational workers & Frequency (\%) \\
\hline Furniture polisher & $02(11.8 \%)$ \\
\hline Poultry worker & $04(23.4 \%)$ \\
\hline Barber & $01(5.9 \%)$ \\
\hline Carpenter & $02(11.8 \%)$ \\
\hline Garment shop worker & $05(29.4 \%)$ \\
\hline Street food seller & $01(5.9 \%)$ \\
\hline Working at tandoor & $02(11.8 \%)$ \\
\hline
\end{tabular}


Only $7 \%$ workers complained of having breathlessness associated with wheezing and $8 \%$ observed to have wheezing even in the absence of cold. $13 \%$ and $24 \%$ workers used to wake up with chest tightness / SOB and attack of cough respectively during the last 12 months as shown below in Figure 2

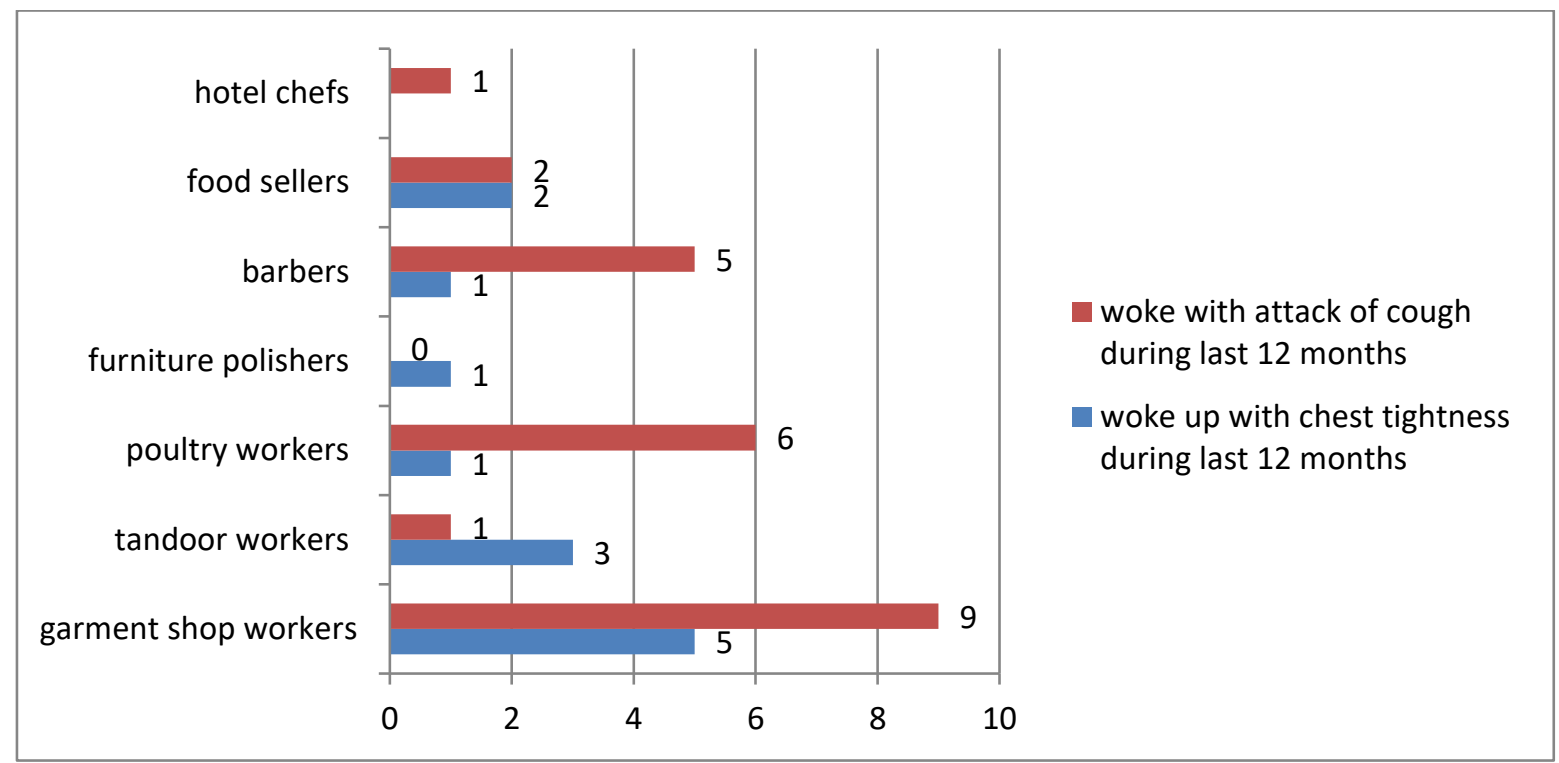

Figure 2: Problem of waking up with chest tightness and cough during last 12 months among daily life Occupational workers

Of the total 41 daily life occupational workers complaining of various respiratory symptoms at their workplace, about 18 claimed the disappearance of these symptoms during holidays. These included 5 barbers, 4 carpenters, 4 furniture polishers, 2 garment shop workers,
1 poultry worker, 1 hotel cook, and 1 tandoor worker. Complaints of wheezing and cough at the workplace among our study participants are illustrated below in Figure 3.

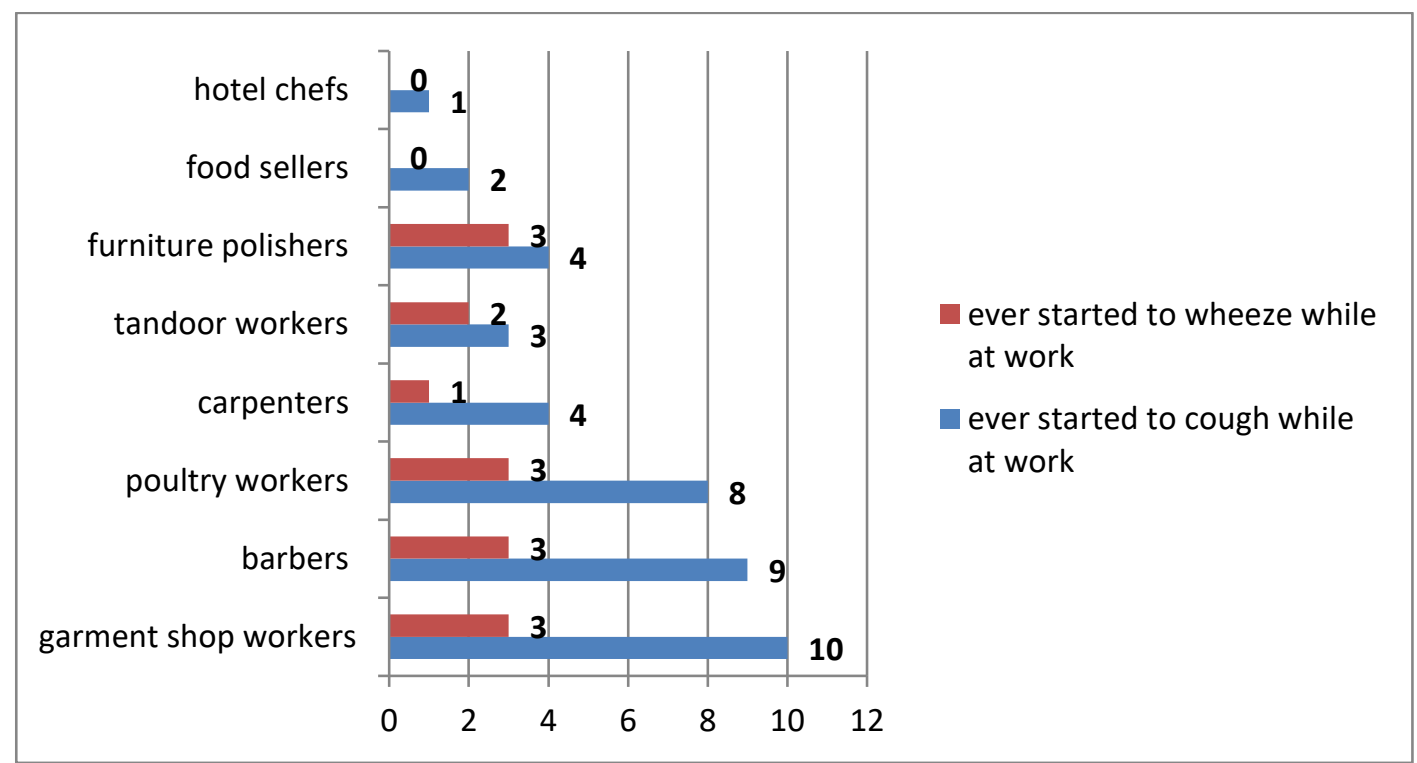

Figure 3: Cough and wheezing at workplace among varied daily life professionals

Most (90\%) barbers followed by $50 \%$ of the garment workers gave history of coughing at workplace. However, mean difference in daily working hours of both types of workers was statistically significant $(\mathrm{P}=0.002)$ as reflected below in Table 2.

Table 2: Mean difference in daily working hours of garment workers and barbers

\begin{tabular}{|l|l|l|}
\hline \multicolumn{2}{|l|}{ Mean working hours / day of daily life occupational workers } & P-value (95\% CI) \\
\cline { 1 - 2 } Garment workers $(\mathbf{n = 2 0})$ & Barbers $(\mathbf{n}=\mathbf{1 0})$ & \\
\hline $10.6 \pm 1.08$ hours & $11.9 \pm 0.9$ hours & $0.002(0.49-2.11)$ \\
\hline
\end{tabular}

\section{Discussion}

Respiratory diseases are known to prevail very frequently among chefs due to poor kitchen ventilation; outdoor or workplace dust exposure and inhalation of biomass fuel [13]. Global Alliance against chronic Respiratory Diseases (GARD) initiated by WHO for curb the chronic respiratory ailments worldwide [14].
In present study, $25 \%$ garment shop workers out of 20 had wheezing and gave history of awakening with chest or breathlessness during last 12 months. $45 \%$ of garment shop workers gave history of awakening with attack of cough in last 12 months while $50 \%$ of garment shop workers were observed to have attacks of cough at workplace. An international study revealed occupational asthma among garment 
workers due to poor ventilation in garment shops and poor control of temperature that may lead to accumulation of formaldehyde which is the proven cause of bronchial irritation or allergic sensitization [15] Numerous studies in textile workers have been carried out but respiratory problems of garment shop workers also need due consideration. Facts in this concern can better be authenticated by doing cohort studies.

In current study, 4 out of 10 enrolled furniture polishers gave history of start of cough during their work. Furniture polishers are exposed to various sensitizers and irritants like glues, dyes, varnishes, and solvents [16]. Similar to our study, $18 \%$ wood processing workers at New Zealand were found to have asthma and cough symptoms as compared to general population [17]. Further research should be carried out among such workers in Pakistan due to deficient literature. 9 out of 10 barbers interviewed in current study were found to have cough at their workplace while 6 gave history of awakening with attack of cough in last 12 months. Barbers being exposed to various chemicals during their job like shampoos, dyes containing formaldehyde, phenols, ammonia etc. are prone to develop respiratory tract reactions and asthma. These chemicals are also known to cause indoor air pollution in salons thus leading to respiratory disorders [18]. Working environment of barbers from their health perspective is in need of great attention.

\section{Conclusion \& Recommendations}

Daily life occupational workers at their workplace are exposed to hazardous agents or poor environmental conditions leading to respiratory or asthmatic problems. There is need to improve workplace environment of daily life occupational workers specially

\section{References}

1. Badar S, Ahmed SW, Mahmood ZA, Khaliq SA, Azhar I, et al. (2016) Occupational asthma: Contribution of smoking and hereditary effects. Iran J Public Health. 45(7): 956-957.

2. Malo J-L, Vandenplas O (2011) Definitions and classification of work-related asthma. Immunol Allergy Clin North Am. 31(4): 645-662.

3. Mapp CE, Boschetto P, Maestrelli P, Fabbri LM (2005) Occupational asthma: state of the art. Am J Respir Crit Care Med. 172(3): 280-305.

4. Dimich-Ward H, Wymer ML, Chan-Yeung M (2004) Respiratory health survey of respiratory therapists. Chest. 126(4): 10481053.

5. Gannon PF, Bright P, Campbell M, O'Hickey SP, Burge PS (1995) Occupational asthma due to glutaraldehyde and formaldehyde in endoscopy and $x$ ray departments. Thorax. 50(2): 156-159.
In present study, 8 out of 9 poultry workers started coughing at workplace while 5 gave history of awakening with attack o cough in last 12 months and 4 reported wheezing any time during last 12 months. On the other hand, 5 out of 14 Spanish poultry workers reported wheezing since last one year. This work-related asthma among Spanish poultry workers was partly attributed to storage mites[19]

in our study, 1 out of 5 hotel chefs not only complained of wheezing at workplace but also gave history of waking up at night with attack of cough during last 12 months. A similar cross-sectional survey by Mohamed TAP et al among Ethiopian hotel chefs revealed that frequent cooking was statistically significantly associated with respiratory disorders among hotel chef (P 0.01) [20]. Likewise, research by Svendsen $\mathrm{K}$ et al elaborated statistically significant relationship of working in kitchen with emergence of respiratory symptoms [21]. Similarly escalated fatalities among Norwegian cooks were attributed to their occupationally associated respiratory diseases [22]. The suppression of such respiratory symptoms could be made possible by reduced exposure to cooking oil fumes. However, the situation in Pakistani set up seems to be grave and strategic planning should be carried out rationally for rectification.

garment shop workers, furniture polishers, barbers, carpenters, poultry workers etc. Personal Protective Equipment should also be used by occupational workers as safety measure.

6. Horwood LJ, Fergusson DM, Shannon FT (1985) Social and familial factors in the development of early childhood asthma. Pediatrics. 75(5): 859-868.

7. Viegas S, Faísca VM, Dias H, Clérigo A, Carolino E, et al. (2013) Occupational exposure to poultry dust and effects on the respiratory system in workers. J Toxicol Environ Health A. 76(45): 230-239.

8. Boskabady MH, Rezaiyan MK, Navabi I, Shafiei S, Arab SS (2010) Work-related respiratory symptoms and pulmonary function tests in Northeat Iranian (the city of Mashhad) carpenters. Clinics (Sau Paulo). 65(10): 1003-1007.

9. Salvi SS, Barnes PJ (2009) Chronic obstructive pulmonary disease in non-smokers. Lancet. 374(9691): 733-743.

10. Lai PS, Christiani DC (2013) Long term respiratory health effects in textile workers. Curr Opin Pulm Med. 19(2): 152-157.

11. Bakirci N, Kalaca S, Fletcher AM, Pickering CAC, Tumerdem $\mathrm{N}$, et al. (2006) Predictors of early leaving from the cotton 
spinning mill environment in newly hired workers. Occup Environ Med. 63(2): 126-130.

12. Khan M, Muhmood K, Noureen S, Mahmood HZ, Amir-ud-Din R (2020) Epidemiology of respiratory diseases and associated factors among female textile workers in Pakistan. Int J Occup Saf Ergon. 1-15.

13. Sultana T, Afzal A, Sultana S, Al-Ghanim K, Shahid T, et al. (2017) Epidemiological estimates of respiratory diseases in the hospital population, Faisalabad, Pakistan. Braz Arch Biol Technol. 60: e17160358.

14. World Health Organization. Chronic Respiratory Diseases.

15. Friedman-Jimenez G. Adult-onset asthma in women garments workers from the Bellevue Asthma Clinic. PA855. Am J Resp Crit Care Med 1994; 4:149.

16. Chamba P, Nunes EA (2016) Work related asthma among workers in wood processing industry: A review. Current Allergy \& Clinical Immunology. 29(2): 110-117.
17. Douwes J, McLean D, Slater T, Pearce N (2001) Asthma and other respiratory symptoms in New Zealand pine processing sawmill workers. Am J Ind Med. 39(6): 608-615.

18. Mandiracioglu A, Kose S, Gozaydin A, Turken M, Kuzucu L (2009) Occupational health risks of barbers and coiffeurs in Izmir. Indian J Occup Environ Med. 13(2): 92-96.

19. Borghetti C, Magarolas R, Badorrey I, Radon K, Morera J, et al. (2002) Sensitization and occupational asthma in poultry workers. Med Clin (Barc). 118(7): 251-255.

20. Mohamed TAP (2021) Respiratory symptoms and other associated factors among the hotel chefs in Gondar Town, Ethiopia. Ind J Sci Tech. 14(21): 1734-1739.

21. Svendsen K, Sjaastad AK, Sivertsen I (2003) Respiratory symptoms in kitchen workers. Am J Ind Med. 43(4): 436-439.

22. Svedahl SR, Hilt B, Svendsen K (2020) Work environment factors and respiratory complaints in Norwegian cooks. Int Arch Occup Environ Health. 93: 205-212. 